\title{
DETERMINING THE CHEMICAL ORIGIN OF THE PHOTOLUMINESCENCE OF CESIUM-BISMUTH- BROMIDE PEROVSKITE NANOCRYSTALS AND IMPROVING THE LUMINESCENCE VIA METAL CHLORIDE ADDITIVES
}

Joonyun Kim ${ }^{1}$, Jinu Park ${ }^{1}$, Sung-Wook Nam², Mingue Shin ${ }^{1}$, Seongmoon Jun ${ }^{3}$, Yong-Hoon Cho ${ }^{3}$ and Byungha Shin ${ }^{1 *}$

${ }^{1}$ Department of Materials Science and Engineering, Korea Advanced Institute of Science and Technology (KAIST), Daejeon 34141, Republic of Korea

${ }^{2}$ School of Medicine, Kyungpook National University, Daegu 41405, Republic of Korea

${ }^{3}$ Department of Physics, Korea Advanced Institute of Science and Technology (KAIST), Daejeon 34141, Republic of Korea

*byungha@kaist.ac.kr

\begin{tabular}{|c|c|c|c|c|c|c|}
\hline \multirow{2}{*}{$\begin{array}{c}\text { Synthesis } \\
\text { method }\end{array}$} & Cs (at\%) & Bi (at\%) & Cs/Bi & \multicolumn{2}{|c|}{ PLQY } & Reference \\
\hline LARP & 14.7 & 85.3 & 0.172 & 1.5 & 22 \\
\hline LARP & 26.8 & 73.2 & 0.366 & 13.1 & 19.4 & Measured \\
\hline
\end{tabular}

Table S1. Atomic percentages of Cs and Bi, as determined by ICP-MS, of the Cs-Bi-Br nanocrystals synthesized by the methods from two recent studies on $\mathrm{Cs}-\mathrm{Bi}-\mathrm{Br}$ nanocrystals.
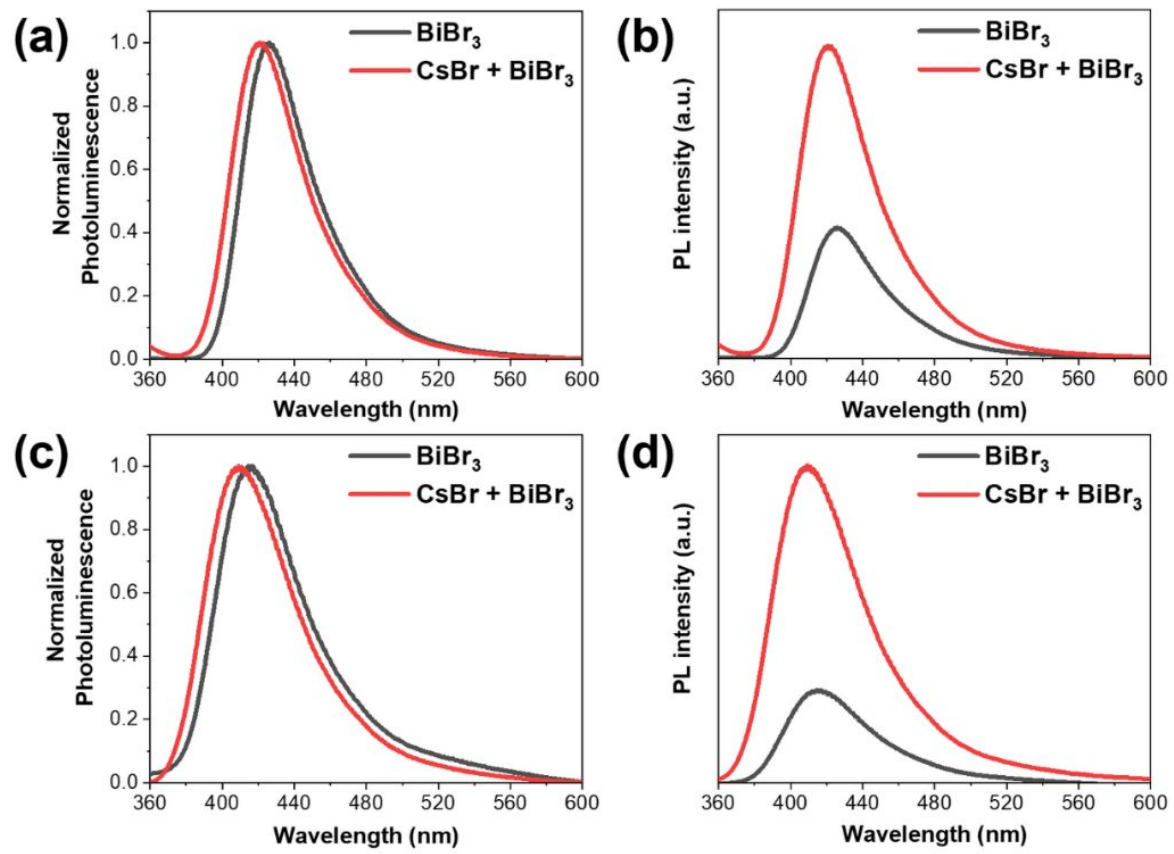

Figure S1. Comparison of normalized (a, c) and raw (b, d) PL spectra using different precursors (only $\mathrm{BiBr}_{3}$ and $\mathrm{CsBr}+\mathrm{BiBr}_{3}$ ) by following the synthesis methods used in the previous studies reported in the literature (a, b): Chem. Commun., 2018, 54, 3779 and (c, d): Adv. Funct. Mater. 2018, 28, 1704446. 


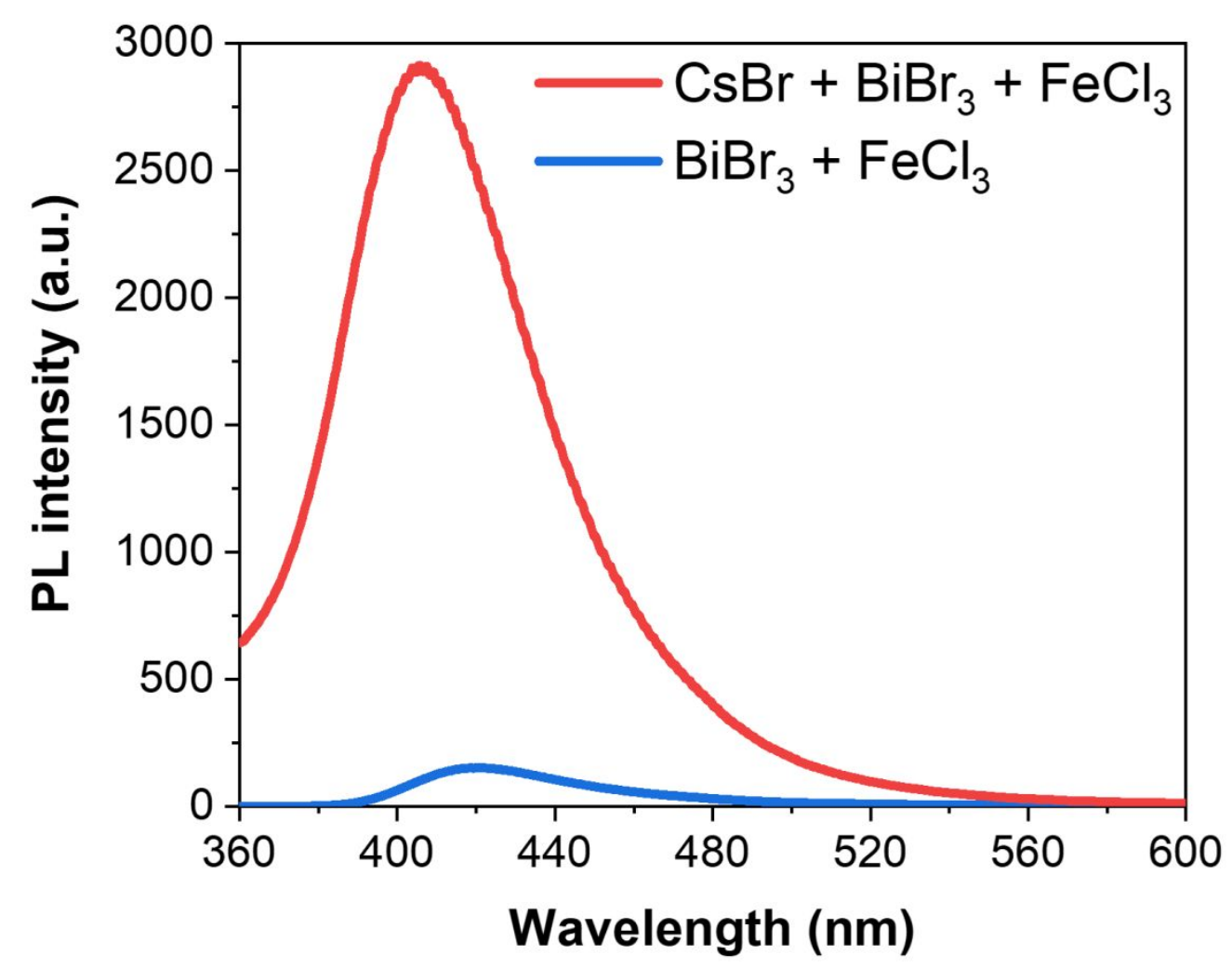

Figure S2. Comparison of PL spectra from NCs synthesized with solutions containing $\mathrm{BiBr}_{3}+\mathrm{FeCl}_{3}($ blue curve $)$ vs. $\mathrm{CsBr}+\mathrm{BiBr}_{3}+\mathrm{FeCl}_{3}$ (red curve).

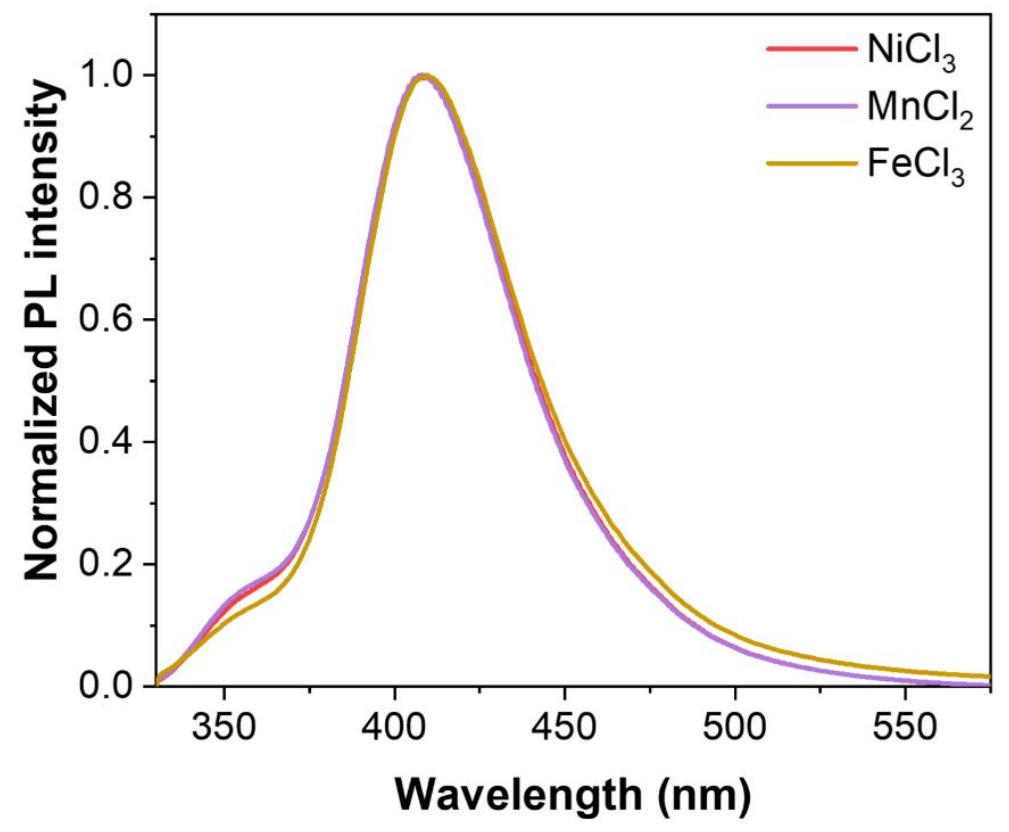

Figure S3. Normalized PL spectra of bismuth bromide nanocrystals with incorporation of various transition metal chloride salts: $\mathrm{NiCl}_{3}$, $\mathrm{MnCl}_{2}$ and $\mathrm{FeCl}_{3}(60 \mathrm{~mol} \%$ of salt was incorporated in each case). The PL excitation source was $300 \mathrm{~nm}$. 


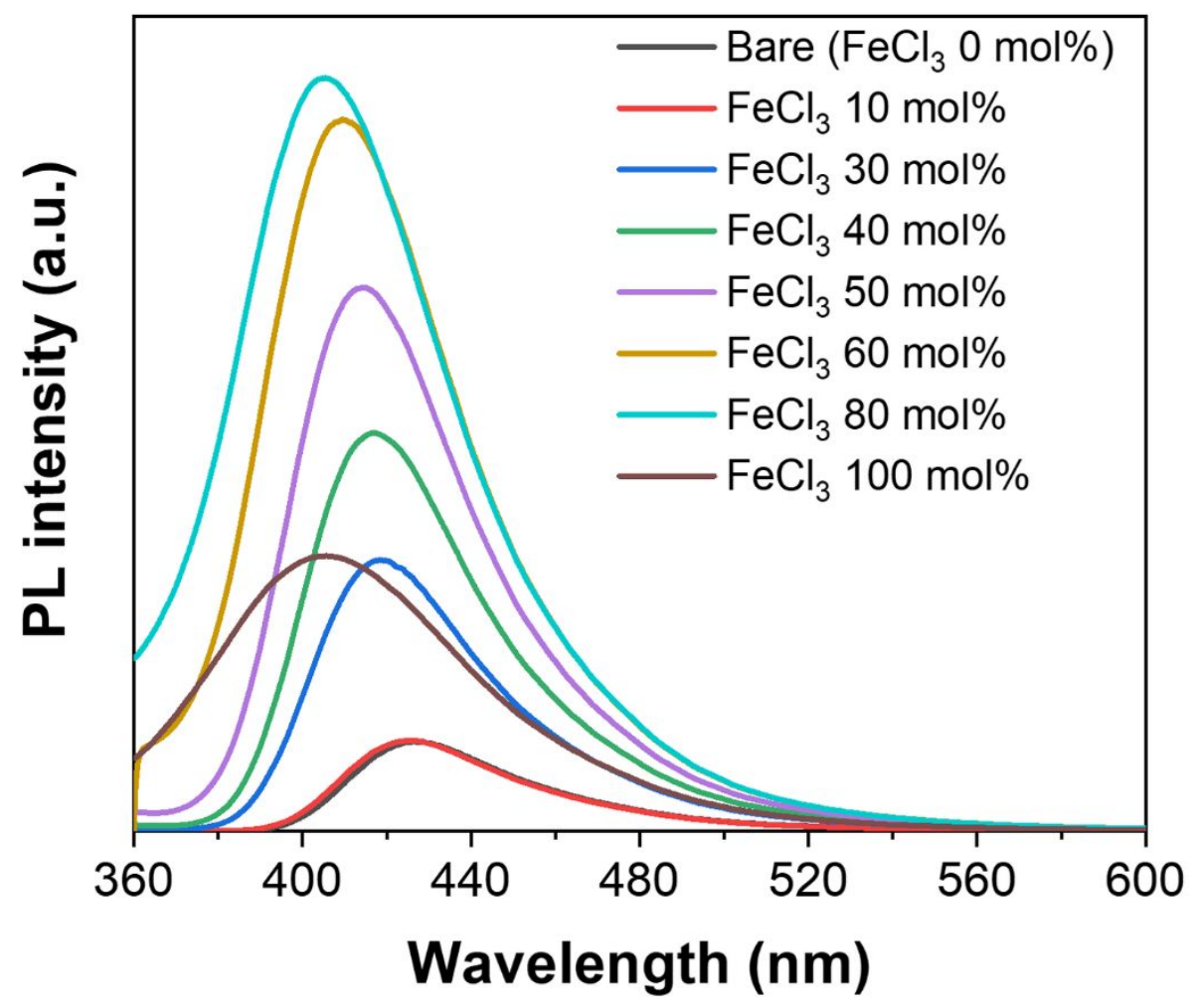

Figure S4. Photoluminescence spectra of Cs-Bi-Br nanocrystals with various mole percentages of $\mathrm{FeCl}_{3}(10-100$ mol\% with respect to the total moles of $\mathrm{BiBr}_{3}$ in the solutions). All spectra were measured at an excitation wavelength at $330 \mathrm{~nm}$. Note the drop in PL intensity with the $100 \mathrm{~mol} \% \mathrm{FeCl}_{3}$.
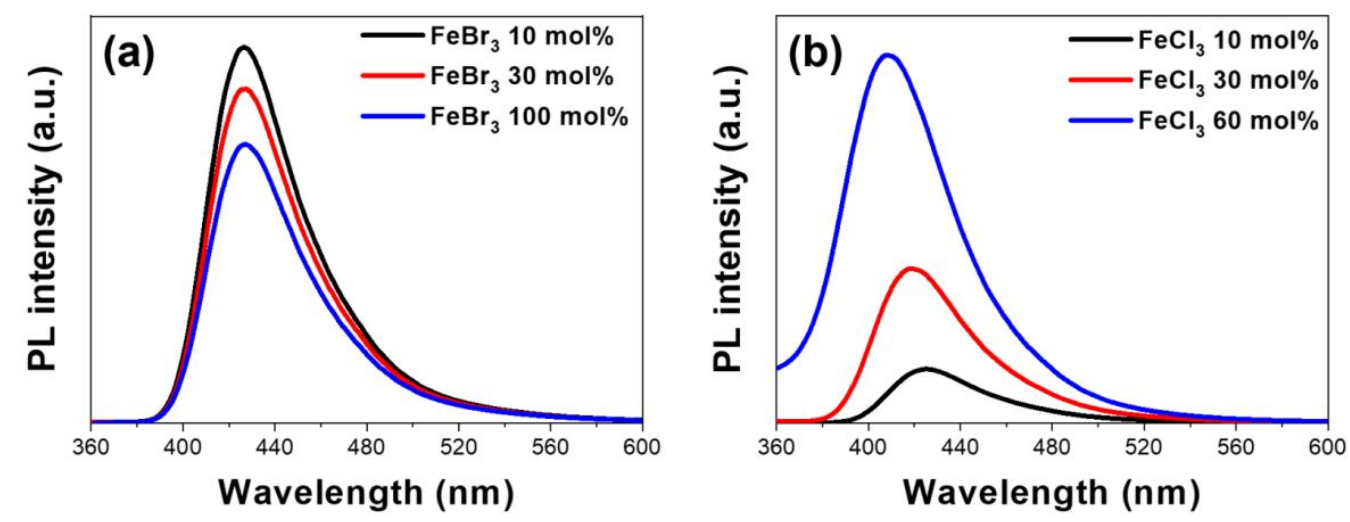

Figure S5. Photoluminescence spectra of $\mathrm{Cs}_{3} \mathrm{Bi}_{2} \mathrm{Br}_{9}$ nanocrystals with different additives: (a) $\mathrm{FeBr}_{3}$, (b) $\mathrm{FeCl}_{3}$. 

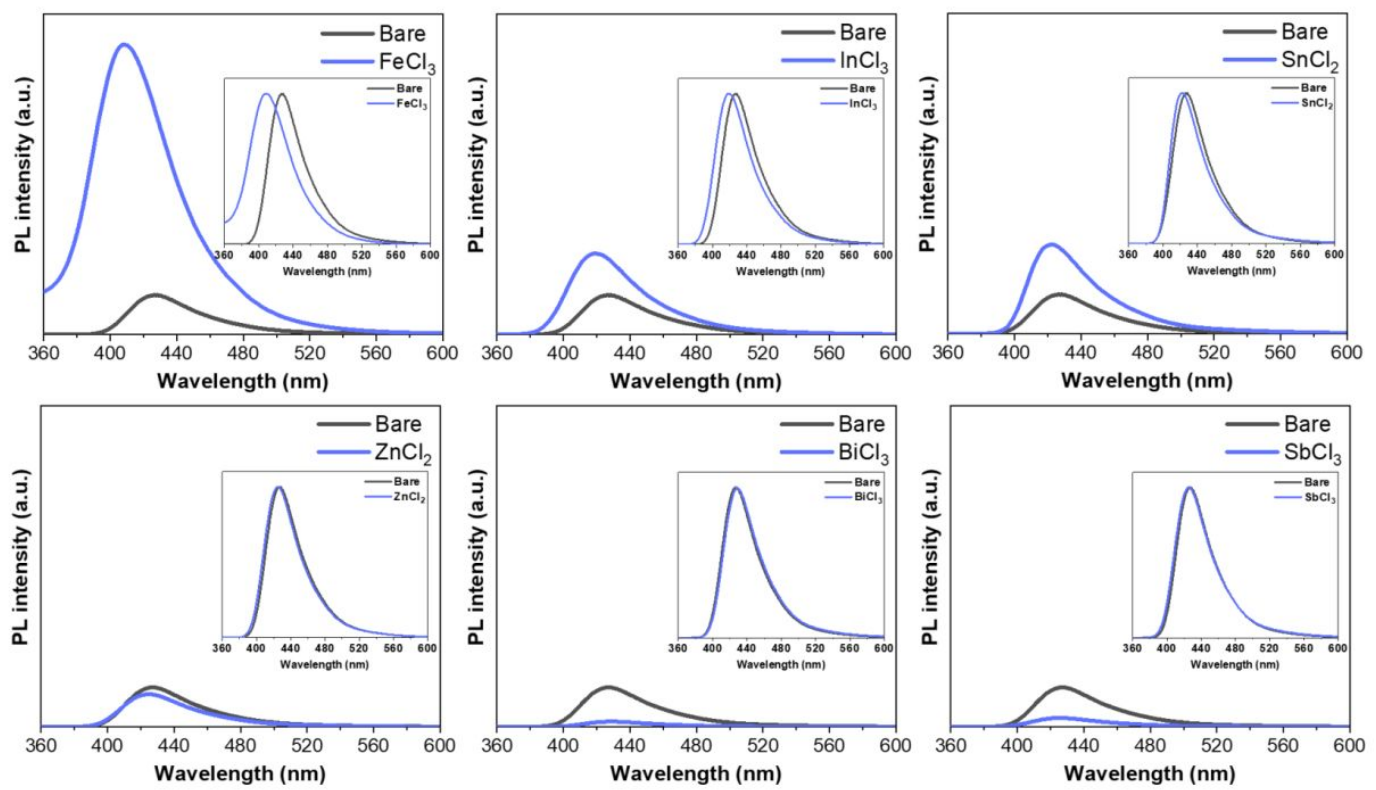

Figure S6. PL spectra of the bare nanocrystals (synthesized with precursor solutions containing $\mathrm{CsBr}$ and $\mathrm{BiBr}_{3}$ ) and the various metal chloride-added nanocrystals, such as $\mathrm{SnCl}_{2}, \mathrm{InCl}_{3}, \mathrm{FeCl}_{3}, \mathrm{ZnCl}_{2}, \mathrm{BiCl}_{3}$, and $\mathrm{SbCl}_{3}$. The molar concentration of the metal chloride additive was $60 \mathrm{~mol} \%$ of $\mathrm{BiBr}_{3}$. The $\mathrm{FeCl}_{3}$ case (the top left figure) is also included for the comparison. The inset in each PL spectrum is a normalized PL spectrum

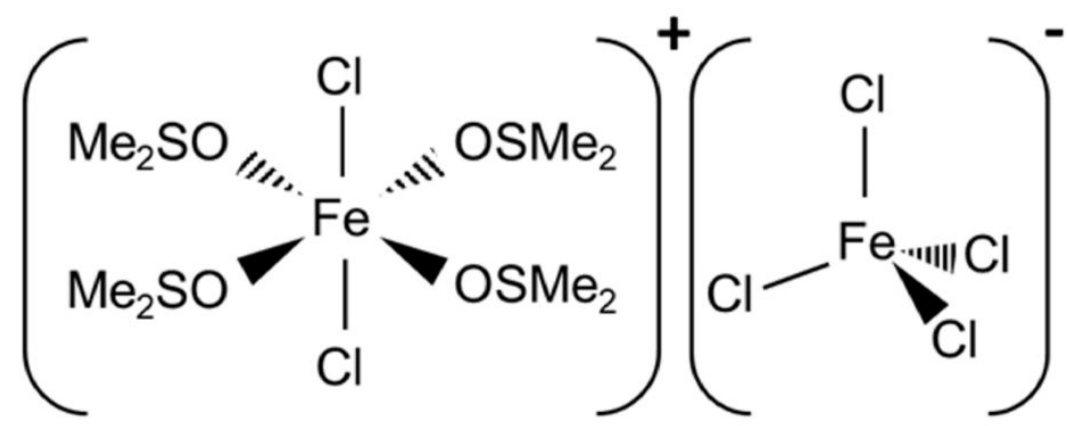

\section{$2 \mathrm{FeCl}_{3} \cdot 2 \mathrm{DMSO}=\left[\mathrm{FeCl}_{2}(\mathrm{DMSO})_{4}\right]^{+}\left[\mathrm{FeCl}_{4}\right]^{-}$}

Figure S7. "Auto-ionized" structure of the $\mathrm{FeCl}_{3}$ complex with DMSO molecules as a ligand 


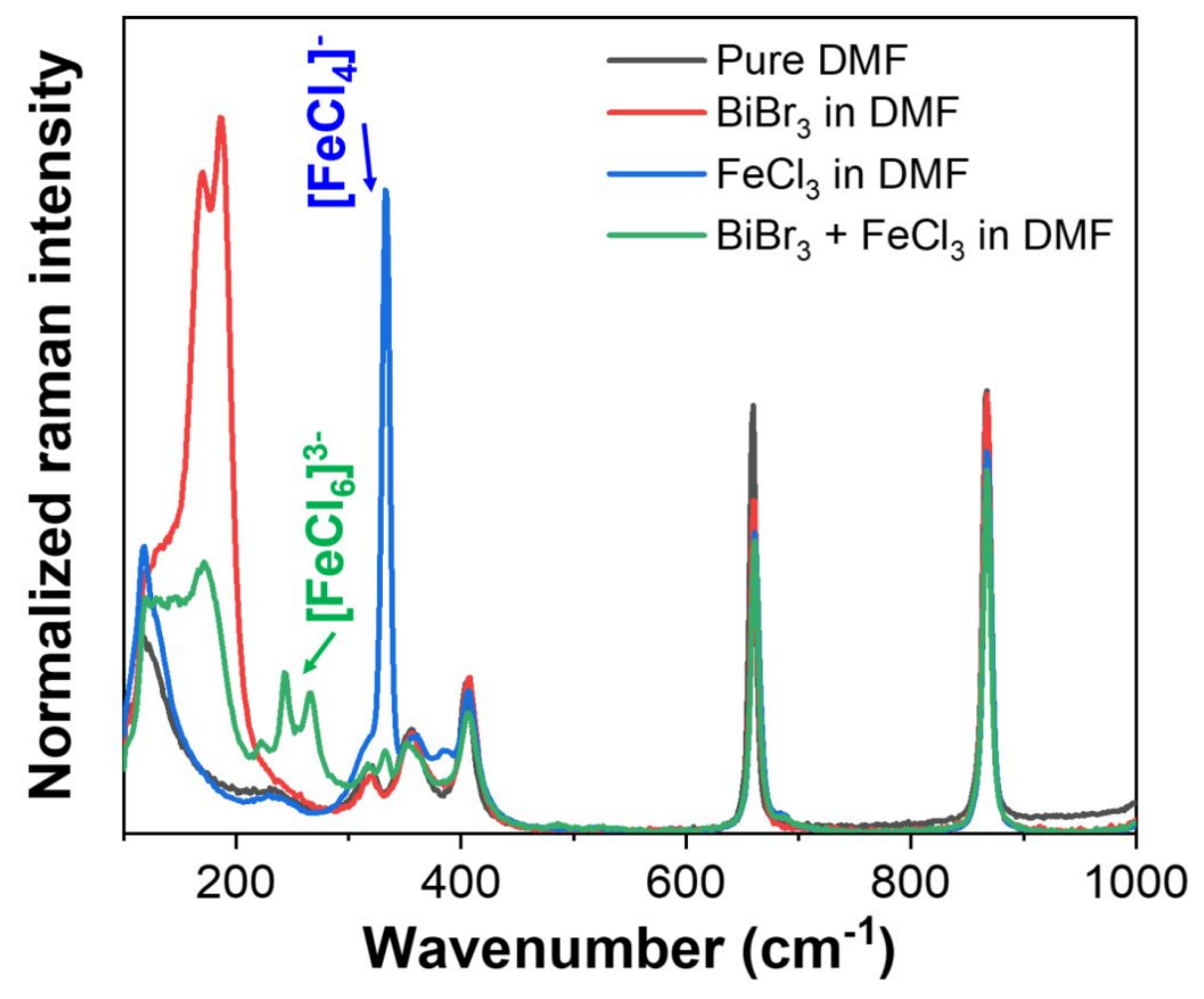

Figure S8. Raman spectra of precursor solutions containing $\mathrm{BiBr}_{3}$ and/or $\mathrm{FeCl}_{3}$ based on a DMF solvent. The sharp peak at $335 \mathrm{~cm}^{-1}$ originates from $\left[\mathrm{FeCl}_{4}\right]^{-}$. For the DMSO solvent, this peak is located close to the C-S-O antisymmetric bend of DMSO. In the presence of $\mathrm{BiBr}_{3}$ in the solution, the $335 \mathrm{~cm}^{-1}$ peak from $\left[\mathrm{FeCl}_{4}\right]^{-}$was quenched and new peaks from $\left[\mathrm{FeCl}_{6}\right]^{3-}$ emerged between $200 \mathrm{~cm}^{-1}$ and 300 $\mathrm{cm}^{-1}$.
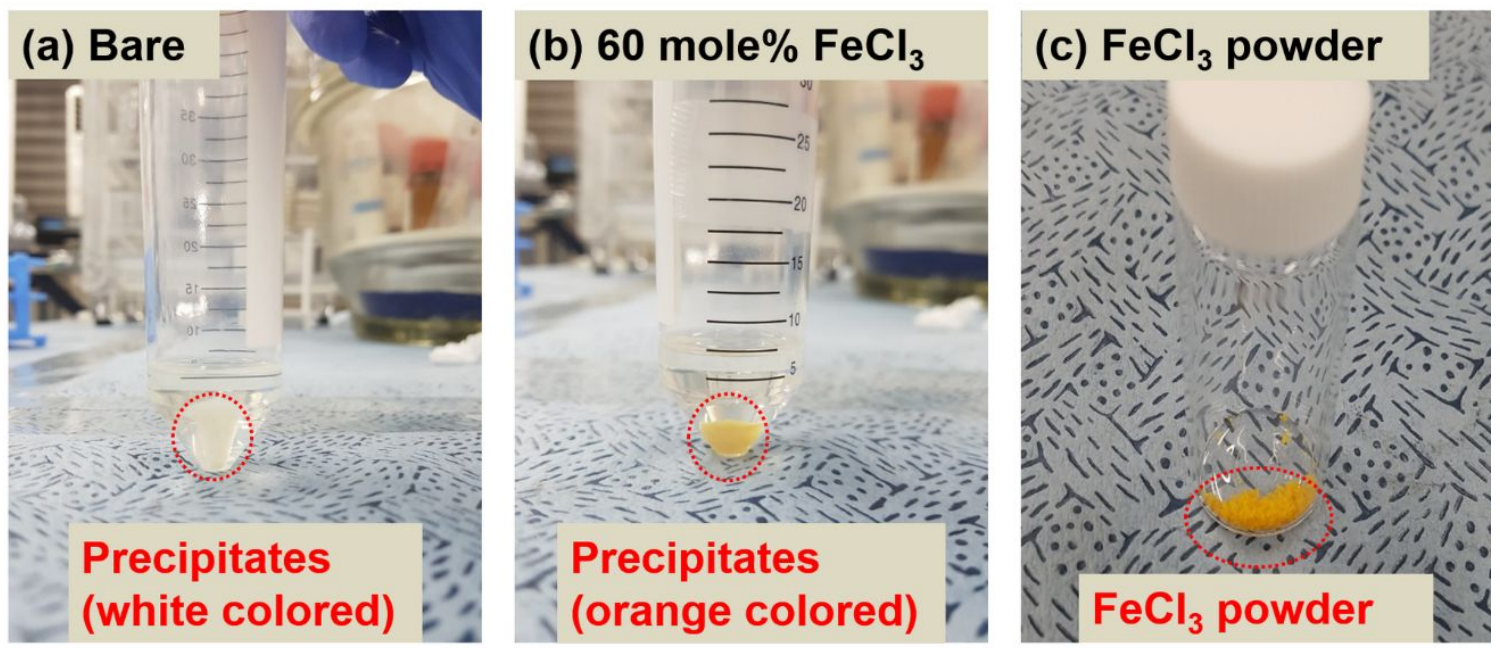

Figure S9. Digital photographs of the precipitates after centrifugation of as-synthesized nanocrystals. (a): $\mathrm{Bare}$ (b): $60 \mathrm{~mol}_{0} \mathrm{FeCl}_{3} . \mathrm{Note}$ that the orange-like color of the precipitates in (b) is similar to $\mathrm{FeCl}_{3}$ powders shown in (c). 


\begin{tabular}{|c|c|c|c|c|c|}
\hline $\begin{array}{c}\text { (a) } \\
\text { Bare }\end{array}$ & $\mathrm{Cs}(\mathrm{at} \%)$ & $\mathrm{Bi}(\mathrm{at} \%)$ & $\mathrm{Br}(\mathrm{at} \%)$ & $\mathrm{Fe}(\mathrm{at} \%)$ & $\mathrm{Cl}(\mathrm{at} \%)$ \\
\hline Norm. At\% & 0.023 & 52.817 & 47.160 & - & - \\
\hline $\begin{array}{c}\text { (b) } \\
\mathrm{FeCl}_{3} 60 \mathrm{~mol} \%\end{array}$ & $\mathrm{Cs}(\mathrm{at} \%)$ & $\mathrm{Bi}(\mathrm{at} \%)$ & $\mathrm{Br}(\mathrm{at} \%)$ & $\mathrm{Fe}(\mathrm{at} \%)$ & $\mathrm{Cl}(\mathrm{at} \%)$ \\
\hline Norm. At\% & 0.432 & 50.465 & 34.740 & 1.534 & 12.829 \\
\hline
\end{tabular}

Table S2. Atomic percentages of elements in (a) bare and (b) $60 \mathrm{~mol} \% \mathrm{FeCl}_{3}$ sample. Both samples exhibit extreme Cs deficiency.

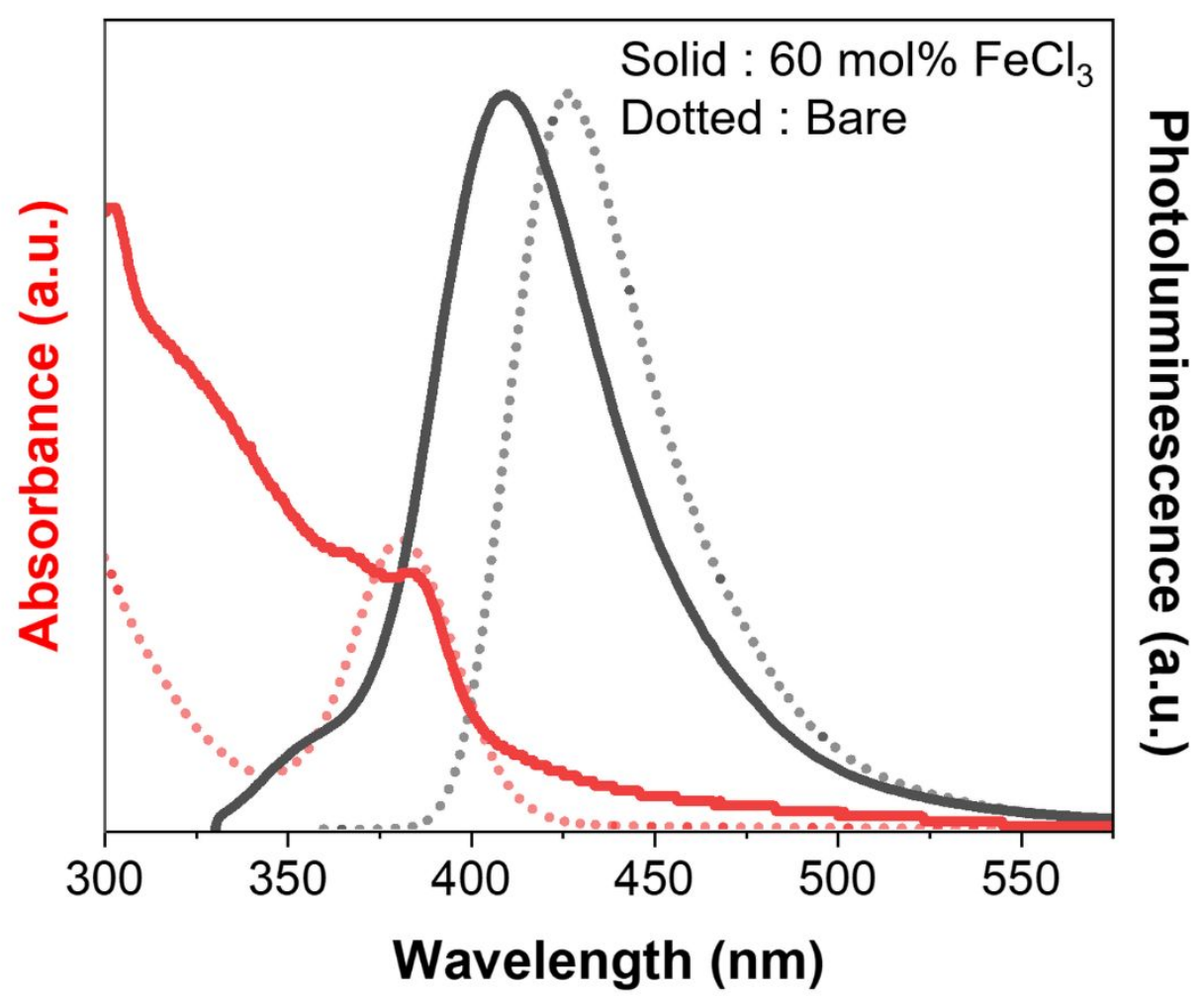

Figure S10. PL (black curve) and absorbance (red curve) spectra of bare (dotted line) and $60 \mathrm{~mol} \% \mathrm{FeCl}_{3}$ ( $\mathrm{solid} \mathrm{line).} \mathrm{The} \mathrm{FeCl}_{3}$ incorporated sample shows a less excitonic absorption feature in the absorbance spectrum. 

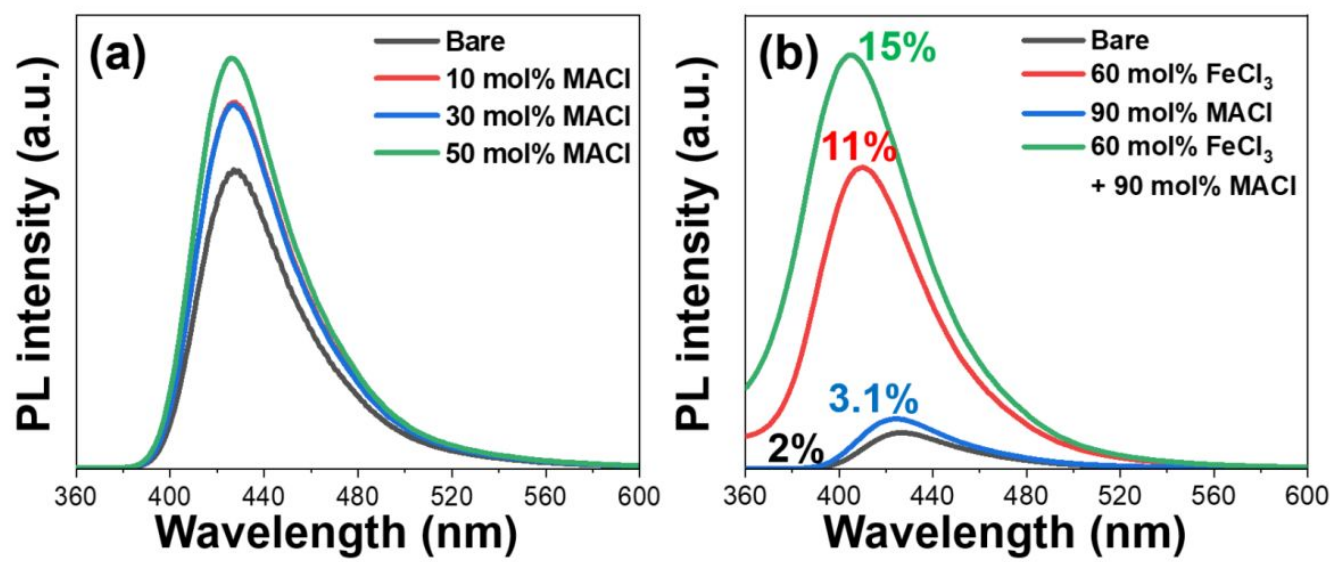

Figure S11. (a) PL spectra of Cs-Bi-Br nanocrystals with different concentrations of incorporated MACl. (b) Comparison of PL spectra with $\mathrm{FeCl}_{3}$ only, $\mathrm{MACl}$ only, and both $\mathrm{FeCl}_{3}$ and $\mathrm{MACl}$ incorporated together. The numerical values in (b) refer to the measured PLQY values. The excitation wavelength was $330 \mathrm{~nm}$.

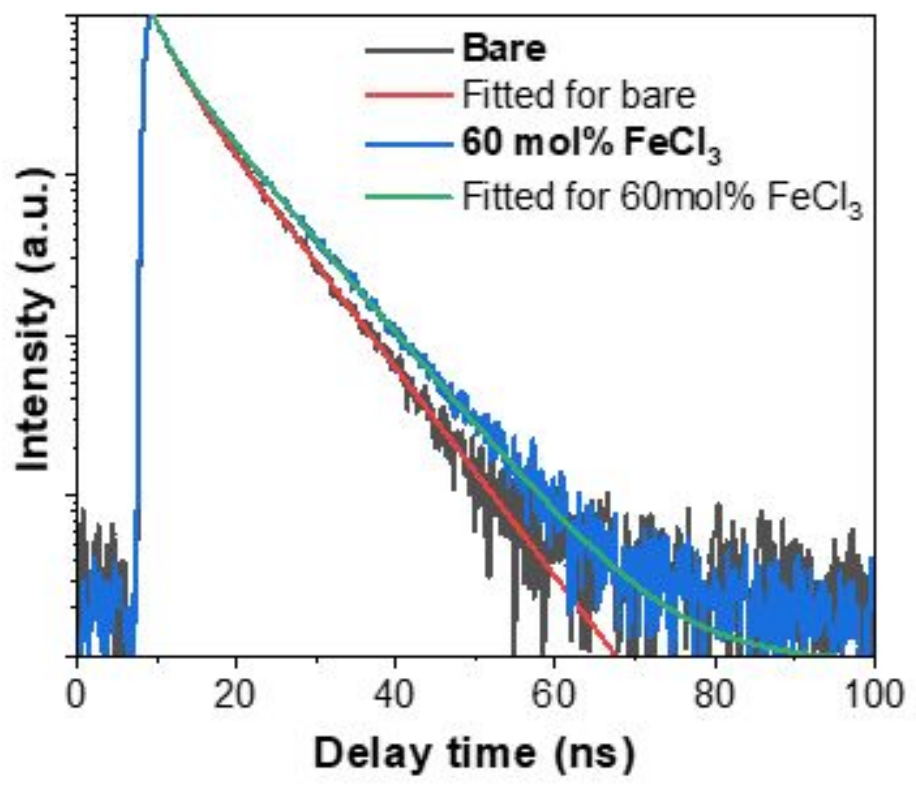

Figure S12. Time-resolved PL (TRPL) data from bare and $60 \mathrm{~mol} \% \mathrm{FeCl}_{3}$. The curves are well fitted with bi-exponential function.

\begin{tabular}{|c|c|c|c|c|c|c|}
\hline & $\mathrm{A}_{1}$ & $\begin{array}{c}\tau_{1}(\mathrm{~ns}) \\
(\text { std. Dev. }\end{array}$ & $\mathrm{A}_{2}$ & $\begin{array}{c}\tau_{2}(\mathrm{~ns}) \\
(\text { std. Dev. }\end{array}$ & $\tau_{\text {avg }}(\mathrm{ns})$ & $\chi^{2}$ \\
\hline Bare & 0.409 & $\begin{array}{c}2.6 \\
(0.064)\end{array}$ & 0.591 & $\begin{array}{c}6.6 \\
(0.038)\end{array}$ & 5.8 & 1.032 \\
\hline $60 \mathrm{~mol} \% \mathrm{FeCl}_{3}$ & 0.408 & $\begin{array}{c}2.5 \\
(0.051)\end{array}$ & 0.592 & $\begin{array}{c}7.5 \\
(0.028)\end{array}$ & 6.5 & 1.123 \\
\hline
\end{tabular}

Table S3. Components for the fitted curve in TRPL using bi-exponential function; $I(t)=A_{1} \exp \left(-t / \tau_{1}\right)+A_{2} \exp \left(-t / \tau_{2}\right)$. 


\section{REFERENCES}

[1] Lou, Y.; Fang, M.; Chen, J.; Zhao, Y. Formation of highly luminescent cesium bismuth halide perovskite quantum dots tuned by anion exchange. Chem. Commun. 2018, 54, 3779-3782.

[2] Leng, M.; Yang, Y.; Zeng, K.; Chen, Z.; Tan, Z.; Li, S.; Li, J.; Xu, B.; Li, D.; Hautzinger, M.P.; Fu, Y.; Zhai, T.; Xu, L.; Niu, G.; Jin, S.; Tang, J. All-Inorganic Bismuth-Based Perovskite Quantum Dots with Bright Blue Photoluminescence and Excellent Stability. Adv. Funct. Mater. 2018, 28, 1704446. 